\title{
Promoting Inclusive Practice: Video CVs as a Teaching \& Learning Tool in the Language Classroom
}

\section{Jennifer Wood}

Modern Languages Department, Prifysgol Aberystwyth University, Wales, UK.

\begin{abstract}
This paper considers the benefits and results of the introduction of a video $C V$ assessment into an intermediate, mixed-ability undergraduate Spanishlanguage class. This task was designed both to modernize an existing written task and to provide students with dyslexia and other language-processing difficulties with the opportunity to best display their capabilities in the second language (L2).

Dyslexia is a Specific Learning Difference (SpLD) whose characteristics can vary in form and severity, but which particularly affect language-processing. Dyslexic individuals often display a "paradoxical co-existence of special abilities and disabilities" (West, 1991, p.32): Abilities which include verbal acuity, visuospatial faculties, flexible problem-solving and creative skills which can all be used to advantage when designing activities to help students achieve success in learning a second language. A multisensory approach is now widely recognised as benefiting dyslexic individuals while other suggested adjustments include: oral recordings rather than written performance; multimedia presentations; and the incorporation of tasks that activate kinaesthetic-tactile components of learning, all elements mobilized within the video CV task.

The video CVs produced by students were multisensory and creative while effectively mobilisiing the L2, showing the benefits of inclusive practice for all students, helping to create a diverse and engaging learning experience.
\end{abstract}

Keywords: Dyslexia; language-processing; multisensory; kinaesthetic; assessment; inclusive practice. 


\section{Introduction}

Dyslexia is a Specific Learning Difference (SpLD) which has a range of common characteristics that can vary in form and severity. Current research suggests that dyslexia is a neurological or neurobiological disorder with a genetic origin (Hudson et al, 2011; Kast et $a l$, 2007), though the exact causes remain enigmatic (Kormos \& Smith, 2012). There is no single coherent theoretical framework for approaching dyslexia (Ramus \& Ahissar, 2012), rather there are several theories that focus on the differing impairments experienced by dyslexic individuals, though most include specific differences in cognitive and neuropsychological functioning (Kormos \& Smith, 2012, p.23). The most accepted theory, or majority subtype, is the phonological processing deficit hypothesis which manifests itself in reduced phoneme-to-grapheme mapping skills, plus minority subtypes characterised by visual/ attentional deficits, though these are by no means the only impairments experienced (see Kormos \& Smith, 2012; Tambour et al, 2016). As dyslexia is a dimensional disorder, it affects people in different ways, while dyslexic individuals often develop both conscious and unconscious compensatory strategies which can mask impairments, problematising diagnoses. Nevertheless, the general consensus is that dyslexia mostly affects individuals with regard to language-related activities or verbal and information processing, engendering difficulties with grammatical and/or lexical pattern recognition, phonological-orthographic processing, visual and auditory processing, and sequencing and organisation which can impact all four linguistic competencies (reading, writing, listening and speaking) while poor working and short-term memory can further impede learning and the development of automacity (Crombie, 2013; Schneider \& Crombie, 2004; Kormos \& Smith, 2012).

This has clear implications for second language learning where standard classroom practices are not always helpful: This is particularly true of natural or communicative methodologies, in which students are expected to infer meaning from the context and receive less instruction in sound-system and syntactical or grammatical rules (Nijakowska, 2010, p.127; Schneider \& Crombie, 2004, p.16). Various studies have shown instead that multisensory approaches or "the simultaneous presentation of linguistic material with the use of as many sensory channels as possible" (Nijakowska, 2010, p.125) are of much more benefit to dyslexic students (see Kast et al, 2011; Wang et al, 2018). Other beneficial approaches include: direct and explicit instruction in the sound-symbol, grammatical, lexical, semantic and sociopragmatic systems of the language (metacognitive strategies); increased exposure to print in the L2, combined with listening and speaking work on the same text (multisensory input); usage of the L2 as the language of instruction in the classroom, keeping the native language for clarification of areas of special difficulty; increased usage of repetition developed across structured stages; the use of mnemonics; and frequent review of elements, since dyslexics "rely on long-term memory, requiring practice and concrete examples for understanding" (Waterfield, 2002, p.22). 
Anxiety, motivation and self-confidence are also strong inhibitory factors for dyslexic students in the language classroom so taking efforts to minimise anxiety-provoking situations, particularly those that have the potential to emphasise any learning difference, and making an effort to improve self-confidence can also have a positive effect. The literature also suggests other beneficial adjustments, such as oral recordings rather than written performance/assessment, multimedia presentations and the incorporation of tasks that involve movable or visual aids and a variety of materials, in order to activate kinaesthetictactile elements of learning, visuospatial faculties, and creative and flexible problem-solving abilities. These kinds of approaches often seek to emphasise the positives of students' learning differences with a focus on students' abilities, not dis-abilities, or on what they can do rather than what they can't, specifically taking into account that individuals with dyslexia often display a seemingly "paradoxical co-existence of special abilities and disabilities" (West, 1991, p.32). These abilities can include verbal acuity, a talent for visuospatial processing, flexible problem-solving abilities, creative/imaginative abilities and an "aptitude for making connections and visualizing global ideas" (Waterfield, 2002, p.22) all of which can be used to advantage when designing activities and assessments to help dyslexic students achieve their full potential in the language classroom. Moreover, the use of such inclusive practices can be of benefit to all students, not just those with dyslexia (Conti, 2017; Crombie, 2013; Kast et al, 2011; Schneider \& Crombie, 2004).

\section{Video CVs}

Video CVs, or video résumés, first appeared in the 1980s but have gained in popularity as a recruitment tool in recent years as the multimedia technology to enable the creation and dissemination of good quality material has become more widely accessible. Video CVs are short recorded audio-visual presentations, normally no more than 3-5 minutes in length, in which applicants can present themselves to a prospective employer. A video CV can be used to replace or supplement a traditional paper $\mathrm{CV}$, but they offer much more scope as they allow applicants to differentiate themselves from others, highlight a particular skill-set or simply showcase their abilities, particularly those that may be difficult to convey via more traditional formats, such as linguistic, communicative or interpersonal competencies. A video $\mathrm{CV}$ can be more creative, individuated and competence-based as "more personalized information is visible through visual and auditory cues" (Hiemstra et al, 2012, p.431). For applicants with language-processing or other impairments a multimedia presentation may also offer the opportunity to circumvent the issues inherent in preparing a paper CV since "video resumes allow [candidates] to compensate for limited language skills or to show acquired skills that are not formalized in education and may remain unnoticed in paper resume screening" (Hiemstra et al, 2012, p.431) and hence to demonstrate their abilities and potential more clearly. 
The format of a video $\mathrm{CV}$ can be designed to meet certain specified criteria or be more unstructured, and can vary from a basic recorded message to a polished multimedia presentation including such elements as subtitles, text/graphic inserts, stop-motion animation, voiceovers and soundtracks. Fundamentally, though, the usage of auditory and visual information is what differentiates the video $\mathrm{CV}$ from a paper one.

\section{The Assessment}

The rationale for re-thinking the traditional assessment regime for this intermediate mixedability undergraduate Spanish-language module was as a response to the growing number of students presenting with information and language-processing issues or SpLDs in these classes (dyslexia, dyspraxia, autism, etc.), as well as from a desire to diversify assessment practices to promote a wider range of linguistic, transferable and employability skills. This task was thus initially designed both to modernize an existing written task - to create a paper CV with accompanying cover letter - and to provide students with dyslexia and other language-processing difficulties with the opportunity to best display their capabilities in the L2.

This task was initially introduced in the first semester of the 2019-20 academic year to a group of 32 undergraduate students (19 female, 13 male), aged 19-32 years, 6 of whom (2 male, 4 female) presented with SpLDs, including dyslexia, a figure slightly above the $5-10 \%$ average (Drabble, 2013, p.7). The class was predominantly L1 English speakers (16 students), plus 11 Polish L1 speakers, 2 French L1 and 1 Spanish, Dutch and Italian L1 speaker respectively. All students presenting with SpLDs were L1 English speakers.

\subsection{Underlying principles}

The task of creating a video CV allowed the students to engage with the L2 in new, multisensory ways and to mobilise different skills and abilities to the ones they would in a standard written assessment, while the nature of the task mirrored the strategies and adjustments suggested for dyslexic students in the literature. Schneider and Crombie (2004), for example, recommend that activities should be designed to "integrate multi-sensory practice" (p.79), emphasizing "learning channels that utilize the dyslexic students' strengths" (p.49), especially by mobilizing "kinaesthetic-tactile components" (p.79). Activities that provide these elements are those that can engage the student through: visual cues and gestures, where auditory input is supported by kinaesthetic, visual and/or textual clues; colour and shape coding, that is the mapping out of structures in visual/graphic ways; the verbalization of and/or the connection of bodily movements with linguistic and semantic concepts; metacognitive strategies; and the staged introduction of concepts. Videos, as teaching input, activate many of these learning channels. They provide multisensory input with audio presentation of the L2 supported by visual clues, where images, actions, gestures 
and behaviours reinforce or translate linguistic expression, alongside textual elements such as subtitles, signage, and so on. Students thus receive "multisensory written and oral, as well as non-verbal, foreign-language and culture input" (Schneider \& Crombie, 2004, p.87). Furthermore, when used as output, with students producing their own videos in the L2, this activates and supports further learning components, such as kinaesthetic-tactile elements and problem-solving skills. Students can submit an oral/visual piece rather than a written text, another of the recommendations for students who struggle with written tasks, and one which allows them to be creative in their response, showcasing their abilities in other areas, such as verbal acuity. Such a task also helps to foster creativity and engage visuospatial faculties, as well as promoting independent learning and improving students' self-confidence, while removing the anxiety of having to perform on the spot, as well as encouraging a more personal engagement with the material.

\subsection{How the assessment worked}

The video CV assessment was embedded within the course syllabus topic of employment, linked to preparation for the Year Abroad. Students were introduced to paper CVs, cover letters and formal letter-writing structures, as well as authentic audiovisual material in the L2 exploring interviews and interview techniques. As an introduction to this assessment, in class students viewed and discussed examples of video CVs in the L2 from Méndez (2020), a blogpost which also includes useful tools and guidance on 'How to create a great video CV'. Students were shown a selection of video CVs which mobilized different approaches and techniques including examples with short interviews, multilingual elements, stop-motion animation, graphics and textual elements, subtitles, humour, etc. Examples which offered cultural input as well as those that highlighted the importance of visual clues and of accessibility, focusing on ability, not dis-ability, were also included. Students were encouraged to analyse the different examples via guided discussion to increase comprehension and point them towards relevant cultural, linguistic, topic-based and assessment-related information, building on previous material and providing a staged introduction to the necessary concepts to complete the task succesfully. This was supplemented by the provision of further resources via the VLE, which also allowed students to reinforce their learning via the opportunity to review material as many times as they wished, an invaluable aide memoire for dyslexic students (Kormos \& Smith, 2012; Wang et al, 2018).

The video CV assessment was not explicitly highlighted as designed for students with SpLDs, rather it was framed as being an assignment to allow students to use multimedia technology in the L2, to activate other skills and to engage with an interesting aspect of the Hispanic recruitment scene. Students were also offered a choice between three assessment tasks, two of which were more traditional written pieces (a paper $\mathrm{CV}$ and cover letter, or an opinion 
piece), the other being the video CV, as detailed below (Fig.1), with more extensive instructions provided via the VLE.

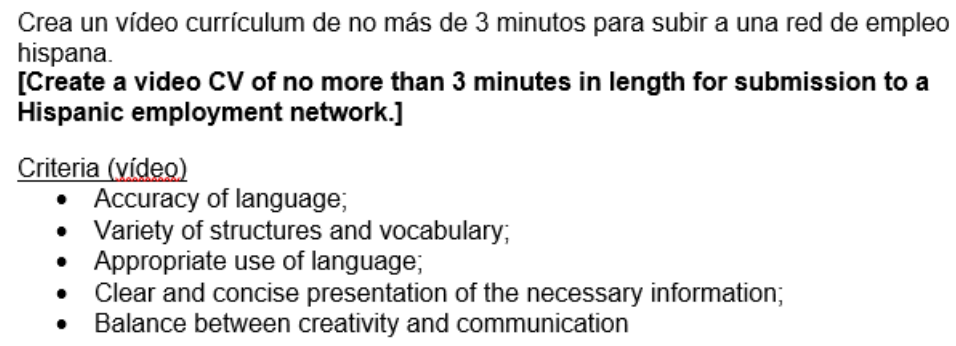

Video limit: The time limit is 3 minutes. Any script will also need to be submitted.

Figure 1. Assessment instructions.

These instructions also explicitly drew on student feedback and analysis of the video CVs discussed in class via the inclusion of the balance between creativity and communication as well as clarity of presentation, providing a greater sense of ownership and more personal engagement with the material.

\section{Discussion}

Only 6 of the 32 students chose the video CV, but those who did were predominantly those who presented with SpLDs (4 to 2) and they had clearly taken a great deal from both the preparatory process and the completion of the task itself. They had evidently engaged with and applied the concepts discussed in class, choosing particular approaches and building certain ideas into their own work. Each video CV was creative, individualized and focused on competencies beyond formalized educational and employment achievements, offering an insight into each student's particular abilities, skills, interests and potential. Their videos also showed off their language skills to great effect with the inclusion of new grammatical and semantic concepts, the mobilization of appropriate topic-related vocabulary and attention paid to pronunciation, fluidity, register and tone. Students also used a variety of approaches, with some presenting themselves more formally on screen while others preferred to use strong visuals accompanied by a voice-over. One student with musical abilities chose to use a sound-track of themselves playing classical guitar to highlight these skills while others chose to use no musical accompaniment but did include graphics to emphasise their points, demonstrating their particular personality and emphasizing communicative and interpersonal skills. Accessibility was another area that students referenced with the choice to use subtitles and also to demonstrate their knowledge of sign-language. Others chose to use strong visual elements, influenced by stop-motion animation techniques transferred to a more technologically manageable format via sequencing the placing of items in front of the camera 
lens at appropriate moments to illustrate their script or the positioning of elements within shot, which showed creativity, problem-solving skills and visuospatial awareness.

Student feedback on this assessment was very positive with comments focusing on the nontraditional format, which allowed them to be creative and to employ audio-visual and multimedia competencies, which reflected the nature and needs of the modern world. Students also appreciated the transferrable and employability skills embedded within the format, of particular use in finding work placements as part of their preparation for the Year Abroad. Those students with SpLDs performed above expectations on this task, achieving an average upward mark-band shift (e.g. 2:1. to $1^{\text {st }}$ ) and showcasing their creative and problemsolving abilities alongside their fluency and verbal acuity in the L2, leading to a subsequent gain in self-confidence.

\section{Conclusions}

The whole class group were able to benefit from engagement with the preparatory process for this assessment and those who completed the video $\mathrm{CV}$ produced work that was multisensory, accessible and creative, while mobilising the L2 to good effect. The task also had a broad appeal as students with declared SpLDs as well as students without completed this assessment showing it to be an effective multisensory teaching and learning tool.

Beyond inclusive practice, there are other benefits to such an assessment. Video CVs offer a diversification of assessment format while also assessing more than one linguistic competency or skill-set, which can also mitigate against reliance on such tools as machine translation software or the likes of Google Translate. As Sager (2020) notes, in designing to guard against such usage, particularly when students are studying at home or online, one strategy "is to diversify assessment formats, relying less on essays and written exams and instead embracing oral exams using Zoom or Skype, or having students produce podcasts, YouTube videos, posters or Prezi presentations that can be shared online" (para.12).

For students, such assessments allow them to display and develop other skills, beyond their linguistic skills, and in the process they also produce something concrete that they can build on, develop and use in the future. Video CVs are an increasing trend in the recruitment marketplace (Hiemstra et al, 2012; Waung et al, 2015) so having the opportunity to work with such material might help students to make an impression on the jobs market.

As this experience shows, ensuring the active participation of students with SpLDs in the language classroom can be successfully achieved by adjusting teaching and assessment practices. Making such accommodations doesn't have to mean lowering requirements or creating multiple, individually-tailored assessments, but rather creating conditions that allow all students to develop and demonstrate their skills and achieve their full potential. 
Adjustments made for learning differences can and do benefit all students and help to create a diverse, creative and engaging learning experience.

\section{References}

Conti, G. (2017, February 5). Are we raising a breed of 'dyslexic' foreign language learners? Message posted to http://www.gianfrancoconti.com

Crombie, M. (2013). Foreign languages for learners with dyslexia - Inclusive practice and technology. In E. Vilar Beltrán, C. Abbot \& J. Jones. (Eds.). (2013). Inclusive Language Education and Digital Technology (pp.124-142). Bristol: Channel View Publications.

Drabble, S. (2013). Support for Children with Special Needs (SEN). RAND Corporation. doi: $10.7249 / \mathrm{RR} 180$

Hiemstra, A. M. F., Derous, E., Serlie, A. W., \& Born, M. P. (2012). Fairness perceptions of video resumes among ethnically diverse applicants. International Journal of Selection and Assessment, 20(4), 423-433. doi: 10.1111/ijsa.12005

Hudson, R.F., High, L. \& Al Otaiba, S. (2011) Dyslexia and the brain: What does current research tell us? The Reading Teacher, 60(6), 506-515. doi: 10.1598/RT.60.6.1

Kast, M., Baschera, G-M., Gross, M., Jäncke, L. \& Meyer, M. (2011). Computer-based learning of spelling skills in children with and without dyslexia. Annals of Dyslexia 61, 177-200. doi:10.1007/s11881-011-0052-2

Kast, M., Meyer, M., Vogeli, C., Gross, M. \& Jäncke, L. (2007). Computer-based multisensory learning in children with developmental dyslexia. Restorative Neurology and Neuroscience, 25(3-4), 355-369.

Kormos, J \& Smith, A. M. (2012). Teaching Languages to Students with Specific Learning Differences. Bristol: Multilingual Matters.

Méndez, C. (2020, June 18). Cómo hacer tu video CV + 20 ejemplos de videocurrículum geniales. Message posted to https://aulacm.com

Nijakowska, J. (2010). Dyslexia in the Foreign Language Classroom. Bristol: Channel View.

Ramus, F. \& Ahissar, M. (2012). Developmental dyslexia: The difficulties of interpreting poor performance and the importance of normal performance. Cognitive Neuropsychology, 29(1-2), 104-122.

Schneider, E. \& Crombie, M. (2004). Dyslexia and Foreign Language Learning. Abingdon, Oxon: David Fulton Publishers.

Shea Sager, C. (2020, March 13). Teaching intelligence: how to take your classes online. Times Higher Education. https://www.timeshighereducation.com/career/teachingintelligence-how-take-your-classes-online

Tamboer, P., Vorst, C. M. H. \& Oort, F. J. (2016). Five Describing Factors of Dyslexia. Journal of Learning Disabilities, 49(5), 466-483. doi: 10.1177/002221941-4558123

Wang, J., Dawson, K, Saunders, K., Ritzhaupt, A., Antonenko, P., Lombardino, L., Keil, A., Agacli-Dogan, N., Luo, W., Cheng, L. \& Davis, R. (2018). Investigating the Effects of Modality and Multimedia on the Learning Performance of College Students With Dyslexia. Journal of Special Education Technology, 33(3), 182-193. 
Waterfield, J. (2002). Dyslexia: Implications for learning, teaching and support. Planet, 6(1), 22-24. doi: 10.11120/plan.2002.00060022

Waung, M., Hymes, R., Beatty, J. E., \& McAuslan, P (2015). Self-promotion statements in video resumes: Frequency, intensity, and gender effects on job applicant evaluation. International Journal of Selection and Assessment, 23(4), 345-360.

West, T. G. (1991). In the Mind's Eye: Visual Thinkers, Gifted People with Learning Difficulties, Computer Images and the Irony of Creativity. New York: Prometheus Books. 